\title{
MODELING OF HANDLING TASK SEQUENCING TO IMPROVE CRANE CONTROL STRATEGIES IN CONTAINER TERMINALS
}

\author{
Uwe Clausen \\ Jan Kaffka \\ TU Dortmund University \\ Leonhard Euler Str. 2 \\ D-44227 Dortmund, GERMANY
}

\begin{abstract}
Free space to expand the handling area in a container terminal is often not available. Therefore terminal operators have to improve operating strategies to increase the capacity of the terminal. For this purpose the authors developed a handling task sequencing strategy with a priority number for a multi crane module in a container terminal. In this paper this control strategy is compared with other state of the art control strategies to find out which crane control strategy is the best strategy for a container terminal. State of the art strategies only consider terminal specific requirements like travel time improvement, but a container terminal is also subject to market requirements such as short waiting times of the vehicles. Those requirements for terminals are often different so that a handling task sequencing is required which can be adjusted to the specific needs of a terminal.
\end{abstract}

\section{INTRODUCTION}

Container terminals can be differed into deep sea container terminals and inland port container terminals. A deep sea container terminal serves the large container ships within the contract time. According to Lee et al. (2008) this is the main issue of deep sea container terminal handling. Large container ships have to be handled as fast as possible so that the lay days remain as short as possible. Unloading/loading of ships and trains is done by cranes, transportation of containers between loading points and stacks by straddle carrier or reach stacker and stacking by crane or straddle carrier. All these subsystems work separated from each other with interfaces between them, hence there is a lot of stochastic influence and interdependency within the terminal operations. This makes an improvement of a whole container terminal very complex and without technical and methodical support hard to handle. Improvements in one subsystem influences all other subsystems and therefore does not result in an improvement for the whole system. On the contrary, inland port container terminals serve as a hinterland hub for deep sea container terminals. Containers from the collecting area are stored in the terminal and delivered just-in-time to the sea port. Furthermore, incoming containers are dispatched in the hinterland to the consignee of the shipment. To ensure the delivery of containers to deep sea terminals in time it is very important that these terminals meet the time tables for trains and barges. In inland port container terminals the main handling equipment are rail mounted gantry cranes on one rail. These cranes straddle all operation areas of the terminal and execute all handlings (see Figure 1). 


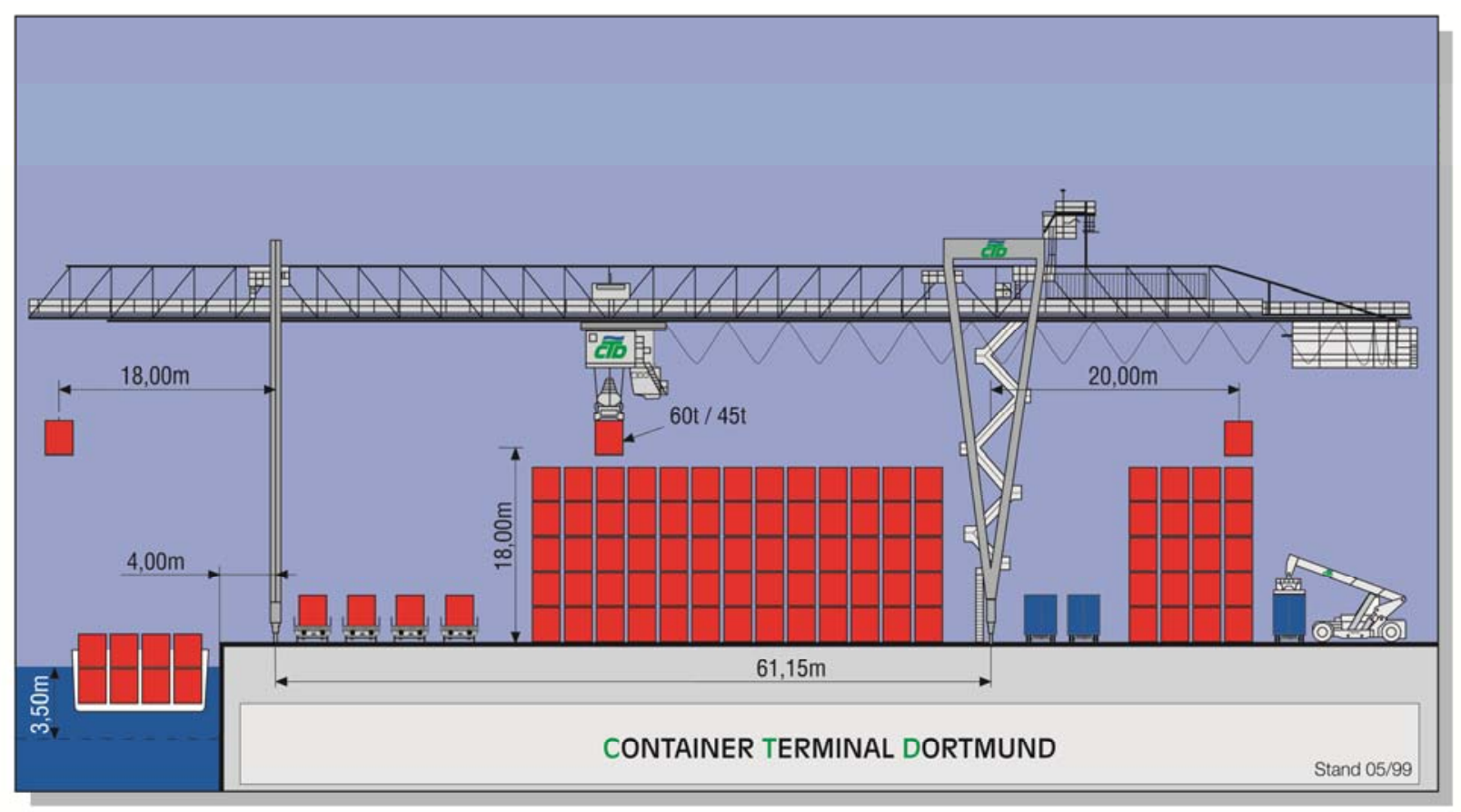

Figure 1: Container handling in inland port container terminals

Stahlbock and Voß (2007) and Steenken, Voß and Stahlbock (2004) provide state-of-the-art summaries regarding operations and methods for optimization in the single subsystems described above. The approaches include optimizations regarding yard planning, berth allocation problems, crane scheduling and transport planning. Meisel andWichmann (2010) developed a container sequencing for quay cranes with internal reshuffles. Gambardella et al. (2001) describe a scheduling for loading and unloading operations in intermodal terminals. Jung and Kim (2006) present a load scheduling algorithm for multiple quay cranes in sea port container terminals. These scheduling approaches are developed for deep sea container terminals. They calculate the optimal sequence separately for each transport mode in deep sea container terminals. In inland port container terminals the cranes handle all transport modes together. Therefore state-of-the-art sequencing approaches are not applicable.

In this paper we develop a handling task sequencing heuristic to improve crane control strategies that satisfies the requirements of inland port container terminals. Canonaco, Legato and Mazza (2007) stated that simulation provides the opportunity to improve the operations in an overall system with all its stochastic influence. It enables the operator to create an experimental model and decide on the best recommended course of action. In this paper we use a simulation approach to implement the heuristic and evaluate its benefits.

This paper is organized as follows. Section 2 discusses crane control including the handling task sequencing. Section 3 describes the simulation suite we developed to simulate container terminals. This simulation suite includes handling task sequencing. Section 4 discusses a case study to apply the approach and show its benefits by the results in section 5. The paper is concluded in Section 6 .

\section{CRANE CONTROL}

The crane area in inland port container terminals is a multi crane module consisting of multiple rail mounted gantry cranes on one rail. The observed terminal in this paper is a typical inland port container terminal in Germany with a throughput of 280.000 TEU per year. The container terminal handles loading units from trains, barges and trucks with 3 handling cranes. Due to the fact that these cranes span the whole handling area of a terminal, crane handlings are the main value added process and therefore the 


\section{Clausen and Kaffka}

control of the cranes offers huge potential to improve terminal operations. The crane control is realized in this paper as a peripheral control unit which controls crane handling online, which means that at every change of system status a new solution is calculated. The main issues considered by the crane control are

- container ground slot allocation and

- handling task sequencing.

Container ground slots are allocated to a container by determining the shortest path from the loading point to possible ground slots or from possible ground slots to the target loading point, if it is known at the time of handling. The ground slot allocation always considers the ground slot restriction, which means that a container stack has a maximum stack height and only containers of the same size can be stacked to one ground slot. Furthermore the container must be stacked in the right stacking zone (e.g., export zone, full container zone) and must be within the effective range of the handling crane. An allocation to other stacking zones or cranes can only happen if the stacking zone or the stack within the effective range of the crane is full. This is allowed to avoid deadlock situations.

The handling task sequencing is the core of the crane control and decides which container is handled next by a crane by calculating savings values for each handling task. This decision is triggered every time the system status has changed (e.g., a crane picks up or drops off a container). In this approach a saving value indicates the handling task with the highest advantage for handling, depending on the calculating strategy used. Savings can be determined by the classical FiFo strategy or Next-Best strategy which handles the task with the shortest travel time to the pick up ground slot as well as with a priority number strategy. The classical strategies are suitable strategies for the purpose of controlling a crane and deliver a good task sequence but only consider company specific requirements like travel time optimization.

However, a container terminal is subject to market requirements too. The main market requirements are the waiting times of the means of transport, especially of ships and trains, but also trucks. If a truck has to stay too long inside the terminal, the forwarder may elect another container terminal for the next time.

The company and market requirements for specific terminals are often different so that a handling task sequencing was developed which can be adjusted to the specific needs of a terminal. This handling task sequencing strategy with a priority number was developed by Lampe (2006) for a solo crane bimodal terminal. The paper enhances this strategy to a multi crane module in a multi modal terminal like an inland port container terminal.

The core of this strategy is the priority number. This number describes in how far a container inside the handling area qualifies for handling. The container with the highest priority number is the best container to handle next by a crane. The priority number consists of a priority parameter for every company and market requirement and their weighting as well as criteria of exclusion. The priority number is calculated by the following term:

$$
\begin{aligned}
& P_{k}=\left(\sum_{i=1}^{n} p_{i} \cdot g_{i}\right) \prod_{j=1}^{m} e x_{j} \\
& \mathrm{k} \in \text { handling tasks; } \\
& p_{\mathrm{i}} \in[0,1] \\
& e x_{j}=\left\{\begin{array}{l}
1, \text { if no criterion of exclusion occurs } \\
0, \text { if a criterion of exclusion occurs }
\end{array}\right.
\end{aligned}
$$

In which $P_{k}$ is the priority number, $n$ is the number of priority parameters, $p_{i}$ are the different priority parameters, $g_{i}$ are their weightings, $e x_{j}$ are the different criteria of exclusion and $m$ is the number of criteria of exclusion.

The priority parameter for every requirement is $p_{i} \in[0,1]$ so that the best task for each requirement is the one closest to one. If the parameter can be higher than one, there is no possibility to compare the dif- 


\section{Clausen and Kaffka}

ferent parameters with each other, because one parameter can be dominant and always overrule the others. The importance of a parameter for the terminal operator can be adjusted by the weighting. The number of priority parameters and their weightings can be adjusted individually to the requirements of the specific terminal. The priority parameters used in this paper with their weightings are shown in table 1. The parameters and weightings were defined in a discussion with the terminal operators of the observed terminal in this paper and represent their specific improvement needs. The priority parameter 'cut off time' represents the departure of a train or barge regarding to their schedule. The weighting of the 'cut off time' rises by 1 every 30 minutes for containers from or to this vehicles to secure the adherence to the schedule. The closer it gets to the cut of time the priority number becomes higher than other priority numbers so that containers with only short time left for the handling will be preferred.

In addition, the priority number has to consider criteria of exclusion (see Table 1), which make a handling of a specific container impossible, by assigning priority numbers to zero. Criteria of exclusion are for example if a collision with another crane can happen if the container is handled, or if the container is inside the pile of a ground slot and other containers have to be handled first to reach this container. If such a criterion of exclusion is calculated for a handling task, the priority number is set to zero.

Table 1: Priority parameters and criteria of exclusion with their weightings

\begin{tabular}{|l|l|}
\hline Priority parameters & Weighting \\
\hline Trip Time & 1 \\
\hline Travel time empty & 2 \\
\hline Waiting time & 2 \\
\hline Cut off time & $\begin{array}{l}\text { Starts with } 1 \text { and rises by 1 every } \\
30 \text { minutes }\end{array}$ \\
\hline Criteria of exclusion & 0 \\
\hline Collision with another crane & 0 \\
\hline Container is inside a pile & 0 \\
\hline $\begin{array}{l}\text { Target vehicle loading point is } \\
\text { not unloaded yet }\end{array}$ & \\
\hline
\end{tabular}

The calculated priority number represents the saving for the handling task. The crane handles the task with the highest saving value. Handling tasks with a saving value of zero are excluded and will not be handled.

\section{SIMULATION SUITE CONTSIM}

The handling task sequencing described above is implemented in a simulation suite called ContSim. The suite was developed by the Institute of Transport Logistics in close collaboration with the Mindener Hafen $\mathrm{GmbH}$ and enables the modeling and simulation of material and information flows in a container terminal. ContSim provides the possibility to model a terminal on a microscopical layer. All handling and controlling processes of the terminal can be modeled and parameterized. Thus, it enables to improve the operating strategies of a terminal with simulation.

\subsection{Input Data}

The simulation suite can use two different data sources. At first it is possible to use real time data from a current system load of the terminal. This approach allows improving a terminal based on the current status. Using real time data gives also the possibility to validate a simulation study by comparing the simulation results with the actual performance of the terminal. In addition to the analysis of current system performance it is often required to evaluate future scenarios with a different system load. Therefore it is necessary to generate input data based on variable input parameters with a data generator. 


\section{Clausen and Kaffka}

Some pieces of information are (more or less) known or can be predicted, like the number of ships and trains arriving and their approximate arriving time, size etc. For other data, like the arrival time of a truck or the storage period of a container, only statistical data can be assumed.

The aim of the data generator is to produce a realistic, truck-based timetable of the form: Truck $x$ brings in container $\mathrm{y}$ on date/time $\mathrm{z}$ and $\mathrm{d}$ days later, it is taken by a ship/train (or the other way round).

The input data we consider are

- (1) The timetable of ships and trains

- (2) Statistical distribution of storage periods, separately for "normal" containers and reefers.

- (3) Statistical distribution of truck arriving times

- (4) Statistical distribution of empty/full containers and different kinds of containers

- (5) Average utilization of ships/trains

- (6) Probability of double handling for containers of different type

The output data consists of a truck timetable of the following form (see Table 2), satisfying the statistical properties stated above. Depending on the double handling probability, some trucks appear twice, taking one container in and another one out.

Table 2: Example of a truck timetable

\begin{tabular}{|l|l|l|l|l|l|l|l|}
\hline Truck & Handling & $\begin{array}{l}\text { Container } \\
\text { number }\end{array}$ & $\begin{array}{l}\text { Container } \\
\text { type }\end{array}$ & $\begin{array}{l}\text { Transport } \\
\text { date }\end{array}$ & $\begin{array}{l}\text { Gate In } \\
\text { (Simulation) }\end{array}$ & $\begin{array}{l}\text { Train/ship } \\
\text { out: date }\end{array}$ & $\begin{array}{l}\text { Train/ship } \\
\text { out: time }\end{array}$ \\
\hline TR 5454 & Full Out & T_Out 35 & 40 & 18.03 .2012 & $09: 33$ & 01.04 .2012 & $06: 00$ \\
\hline
\end{tabular}

Starting from the fixed timetable of ships and trains, the data generator generates containers and afterwards produces trucks for them. The procedure for a container arriving by ship and leaving by truck (as all other cases are similar) can be described as followed:

For a ship coming from (1) a number of containers is generated according to the statistical distributions (4) and (5). For such a container a truck is produced fetching it; its arrival time is chosen according to (2) and (3).

Until now, all trucks are single handled. To reach the double handling probability stated in (6), the generator iteratively deletes trucks and gives their duties to existing trucks. Of course, this induces small changes in the statistical distributions (2) and (3), but as the generator always couples trucks which are very near to each other in the timetable, the effect is negligible.

Furthermore, the user can decide whether Saturdays and Sundays should be ignored in the generation of the truck timetable (which might result in an increasing amount of containers stored during the weekend).

\subsection{Elements of ContSim}

Regarding to Voss (2007) the typical structure of a container terminal consists of two external interfaces: first, the quayside loading points, where containers are loaded on/off ships; second the landside loading points, where containers are loaded on/off trucks and trains. Inside the terminal, containers are stored in container stacks with different zones for varying types of containers. Basically, stacking zones can be distinguished into import and export zones. Export containers are containers for trains and ships which are announced for this day or the following day. This classification is extended by zones for full and empty containers, containers with dangerous goods and for reefer containers. Additionally, inland port container terminals contain zones for trailers and swap bodies, which are not handled in sea port container terminals.

A container stack is grouped into ground slots on which containers are stacked in a pile with a certain maximum height. The authors assume that the dimension of a ground slot is equal to a 20 feet container. This means that 40 feet containers are stored on two ground slots. Furthermore it is assumed in the simulation suite that a container can only be stacked onto a container with the same size. The maximum height of the container pile is restricted either by the controlling strategy or by the handling equipment. 


\section{Clausen and Kaffka}

The developed simulation suite ContSim contains all necessary components to map the handling processes of a container terminal. The suite is based on the simulation software ED TransSim Node including ED Logistics. Figure 2 shows the Elements of ContSim.

The System boundaries of the simulation suite are the transition to the terminal estate (e.g., the gateway from the street to the parking area, the loading track) on the landside and the quay on the seaside. In addition ContSim provides streets, rail- and waterways to model the way of the vehicles to the terminal, but operation and controlling strategies only affect elements inside the system boundaries. It is possible to map the handling processes of every inbound and outbound container. Vehicles are created by different vehicle generators for each means of transportation. The input tables of the generators are prepared real time data or tables created by the data generator described in section 3.1.

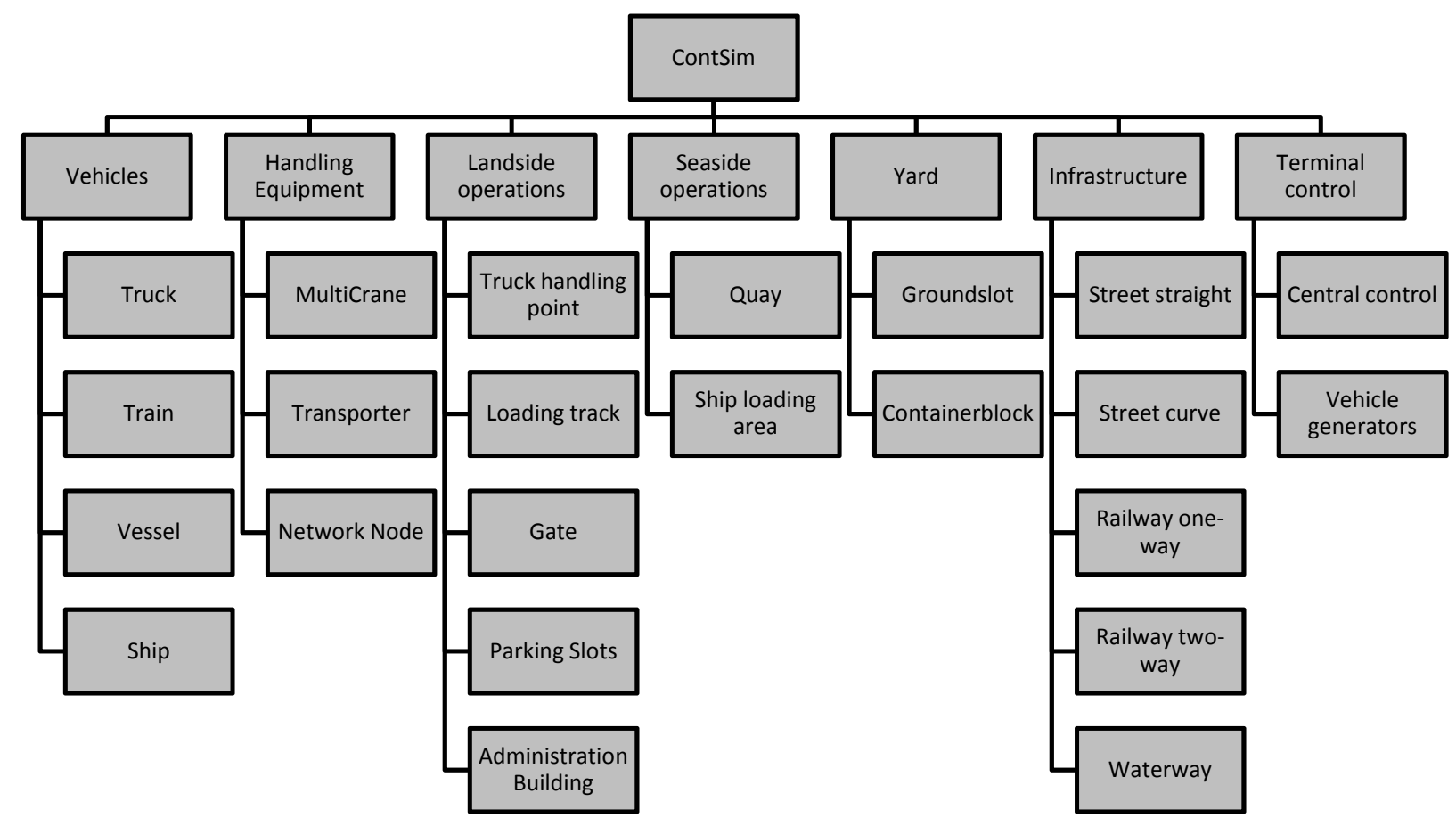

Figure 2: Elements of ContSim

A central control element improves control strategies regarding the layout of the yard, loading point allocations and human resource decisions.

Handlings in ContSim are possible with cranes and transporters. The crane element can act as a quay crane or as a gantry crane and the area of action can be adjusted. The transporters can act as an AGV, straddle carrier or a reach stacker. Cranes and transporters are controlled locally, so that they act selfsustaining in the handling system of the terminal. The controlling heuristics used to control the cranes presented in section 2 are implemented in the crane element. Transporters are linked to a network consisting of different network nodes and edges, which connect the nodes. To ensure the correct use of the transporter, the network has to include every possible pick-up- and drop-off-point for containers. The shortest travel path in this network is calculated by a Dijkstra algorithm.

As an example for the function of ContSim the truck handling process is considered. A truck arrives at the terminal and parks at a parking lot. The driver walks into the administration building for registration. At this event the central control element calculates the optimal truck handling point. If a handling point is found, the truck is free to enter the terminal. Otherwise the truck has to wait until a suitable handling point is available. The truck enters the terminal at the gate. Depending on the handling category (retrieve or deliver a container, container is empty or full, etc.) the workflow at the gate is different. A truck 


\section{Clausen and Kaffka}

which only retrieves a container has almost no time consumption at the gate. A delivered empty container has to be checked if it is damaged or not. In the case of a damaged container, keeping record of the damage takes extra time. If the truck delivers a full container for export, the seal of the container has to be checked. The different scenarios consume different time and are implemented in ContSim. As a next step the truck drives to the assigned truck handling point where the responsible handling equipment handles the truck depending on the handling category described above. After the handling is finished the truck leaves the terminal at an exit gate.

\section{CASE STUDY}

The simulation suite ContSim is used to evaluate the benefit of using the handling task sequencing (described in section 2) instead of a sequencing based on the next-best strategy for controlling the cranes in the terminal. Figure $3 \mathrm{a}$ and $3 \mathrm{~b}$ show the two and three dimensional model views of the terminal.

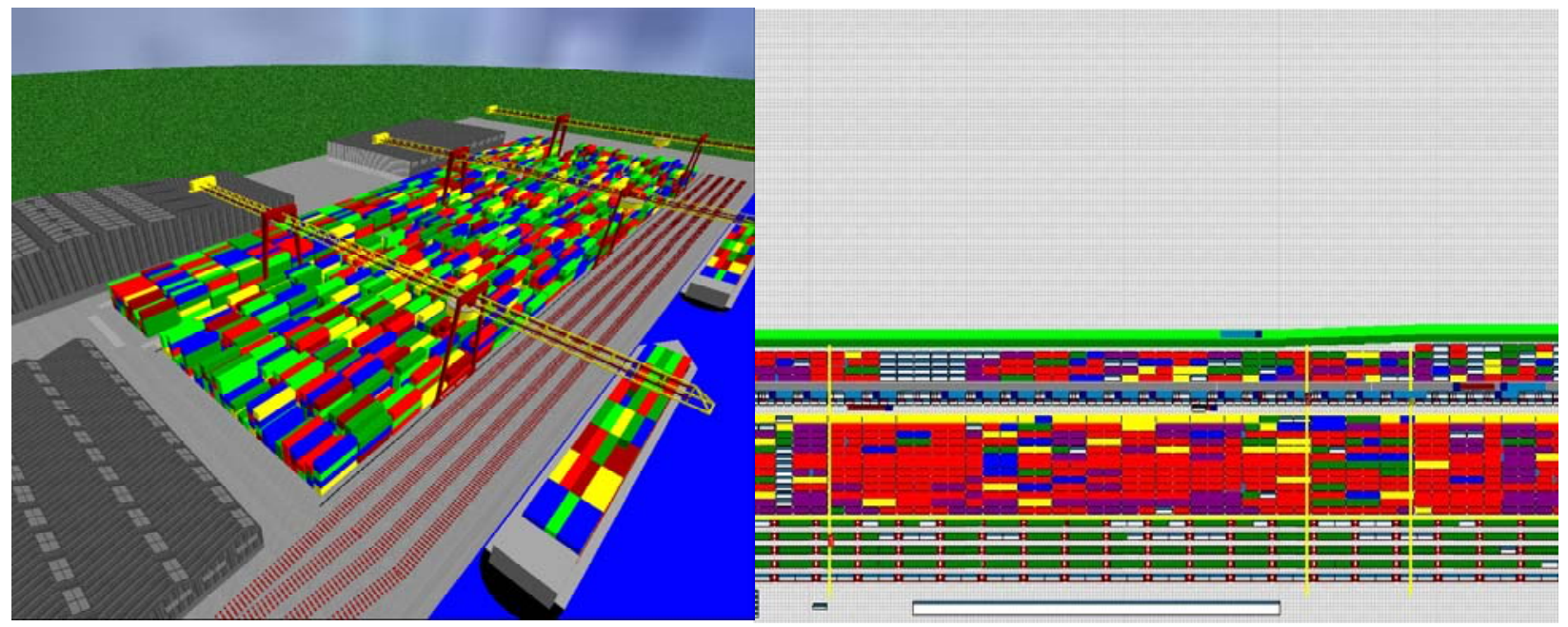

Figure 3: (a) 3-D and (b) 2-D simulation models of the container terminal

The observed terminal has the following scope:

- 3 handling cranes,

- 1000 ground slots,

- maximum stacking height of 5 Containers,

- 4 loading tracks for trains with a length of 400 meters each,

- 400 meter quay for 2 barges,

- 20 loading points for trucks,

- handlings of 1000 containers a day.

Generally all handling processes in the container terminal are done by three cranes. The cranes have separated effective areas which overlap for a small area between the cranes. In the layout the export containers are located at the overlap areas, and each crane has a separated area for empty containers and input containers.

The input data for the simulation model are real time data evaluated from the past year. The handling processes and layout data were recorded on site. Process times are based on time measurements. Based on this we modeled the terminal on a microscopical layer. Thereupon the real time data and expert interviews with the terminal operators were used to validate the model.

The simulation model is tested with the following two different crane task sequencing strategies

- Next-best and 


\section{Clausen and Kaffka}

- Priority number with the adjustment described in section 2 (parameters: short truck waiting time, short travel-times and adherence to schedule, see Table 1).

Due to this, the experimentation plan includes two different scenarios. Every scenario was simulated 20 times to avoid statistical runaways.

\section{RESULTS}

The experiments to evaluate the best operating strategy bundle for the specific terminal are based on the current system load of the terminal. After that, a new maximum throughput will be determined.

The bundle of operating strategies in the case of this terminal consists of the crane control explained before. Currently the terminal is operated with the Next-Best handling task sequencing and the current system load is the maximum throughput possible with this task sequencing. With the use of the handling task sequencing with priority number the terminal can reduce the time of a truck at a loading point by 6 $\%$. This means an improvement of 1.8 minutes per truck. Therefore more trucks can be handled in the terminal which increases the capacity of the terminal.

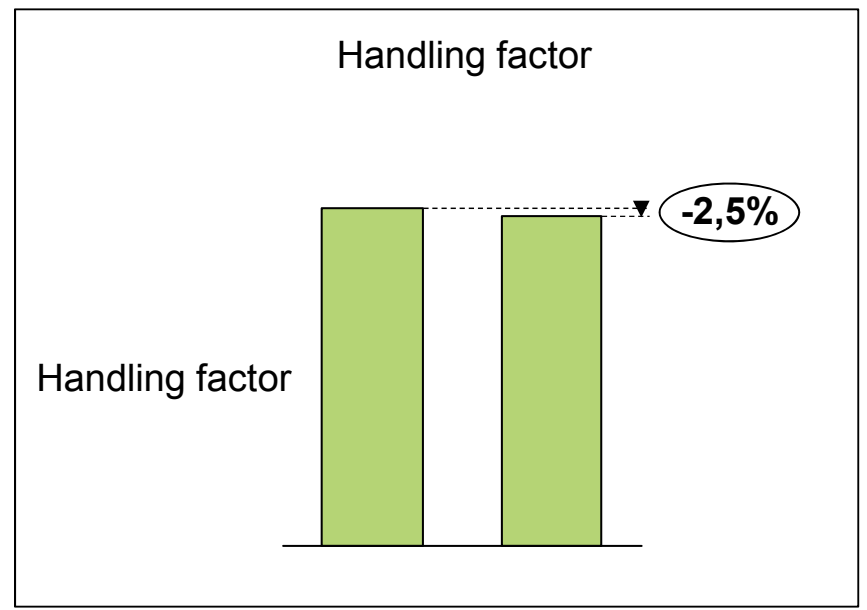

Figure 4: decrease of handling factor

Another important figure is the handling factor. This figure describes the ratio of unpaid handlings to paid handlings. The terminals get only paid for the handling of a container from one vehicle to another vehicle. Every handling to the depot and depot to depot handling due to reshuffling is not paid and decreases the possible number of paid handlings. In a terminal without direct handlings, like in every inland port container terminal, the lowest handling factor which can be reached is 1. Every container is at least handled from a vehicle to the depot and from the depot to a vehicle. This means 2 handlings, one paid handling and one unpaid. The intention of a terminal is to lower this factor as near as possible to 1. A low factor indicates that less depot to depot handlings were done and the productivity of a crane is raised. Due to identifying the best strategy mix, the handling factor can be decreased by $2,5 \%$ (Figure 4). This means the depot to depot handling are reduced by 20 . In addition, the empty travel ratio of the cranes can be reduced and the full travel ratio of the cranes can be raised by $4 \%$. Furthermore, the efficiency of all cranes in the terminal is more uniform. Due to more capacities at the loading points and increased productivity of the cranes, the terminal operator has the opportunity to raise the maximum throughput of the terminal.

After changing the handling task sequencing the new maximum throughput is determined with this strategy bundle. Therefore, experiments were taken with slowly rising system loads until the terminal system reaches its limits regarding the utilization of the yard and the adherence to schedules. At this point the maximum throughput is reached. The maximum throughput of the terminal could be raised by $30 \%$ based on the best operating mix. 


\section{Clausen and Kaffka}

With the simulation and the implemented controlling strategies, especially the handling sequencing with priority number, we were able to increase the efficiency of the cranes and reach a uniform productivity in a multi crane module compared to the current situation. Furthermore, we lowered the cycle time of the trucks, and met the schedules for ships and trains. In addition, we lowered the direct handling factor. The lower this factor is, the more financial benefit the terminal has.

\section{CONCLUSION AND OUTLOOK}

This paper showed that handling task sequencing with priority number is more efficient than the standard strategy next-best and enhances the performance of the inland port container terminal. It also showed that improvement with simulation brings a benefit for terminal operators. Bottlenecks in the material flow can be identified with the simulation suite and new strategies can be tested in a virtual model, without costintensive real time tests. The suite can also be used as a daily control panel to plan the deployment and the operating strategy mix for the upcoming day.

As a next step we develop new approaches to improve the container ground slot allocation in the crane control. The approach in this paper is a very simple shortest path calculation with little restriction given by the zones of the layout. We will develop a heuristic which takes more operating factors into account (e.g., loading order of the modes of transport) and will integrate the allocation into the container task sequencing. Hereby, we want to reduce double handlings of containers and reduce the number of calculated criteria of exclusion.

\section{ACKNOWLEDGMENTS}

The presented results are parts of the work from the research project "Hafenband am Mittellandkanal" within the competition "Logistik.NRW" funded by the North Rhine-Westphalia Ministry for Economy, Energy, Building and Traffic and co-founded by the operational program "Regionale Wettbewerbsfähigkeit und Beschäftigung" of the European Founds for Regional Development (EFRE) which takes place in cooperation with the Mindener Hafen GmbH.

\section{REFERENCES}

Canonaco, P., Legato, P. and Mazza, R.M. 2007. An integrated simulation model for channel contention and berth management at a maritime container terminal. 21st European Conference on Modelling and Simulation, $353-362$.

Gambardella, L.M., Mastrolilli, M., Rizzoli, A.E. and Zaffalon, M. 2001. An optimization methodology for intermodal terminals management. Journal of Intelligent Manufacturing, 12, $521-534$.

Jung, S.H. and Kim, K.H. 2006. Load scheduling for multiple quay cranes in port container terminals. Journal of Intelligent Manufacturing, 17, $479-492$.

Lampe, H. 2006. Untersuchung von Dispositionsentscheidungen in Umschlagterminals des kombinierten Verkehrs Straße/Schiene. Phd Thesis. TU Dortmund University.

Lee, W. S., Ottjes, J. A., Veeke, H.P.M. and Rijsenbrij, J.C. 2008. Using container call time information for restacking reduction. Industrial Simulation Conference'2008, 293 - 298.

Meisel, F. and Wichmann, M. 2010. Container sequencing for quay cranes with internal reshuffles. OR Spectrum, 32, 569-591.

Stahlbock, R. and Voß, S. 2007. Operations research at container terminals - A literature update. OR Spectrum, online http://www.springerlink.com/content/018j57r4364148m0

Steenken, D., Voß, S. and Stahlbock, R. 2004. Container terminal operation and operations research - a classification and literature review. OR Spectrum, 26, 3-49.

Voß, S. 2007. Container terminal operation and operations research - recent challenges. Proceedings of the 12th international Conference of Hong Kong Society for Transport Studies - Transportation Systems: Engineering \& Management, 387 -396 


\section{AUTHOR BIOGRAPHIES}

UWE CLAUSEN is the managing director of the Institute of Transport Logistics at the TU Dortmund University and director of the Fraunhofer-Institute for Material Flow and Logistics (IML). Prof. Dr.-Ing. Clausen studied computer sciences at the University of Karlsruhe (TH) and finished his doctoral thesis on transportation network optimization at TU Dortmund University in 1995. Afterwards, he worked at the "Deutsche Post AG" and joined Amazon.de in 1999. As operations director he was responsible for setting up the new Amazon Logistics Center in Bad Hersfeld. In 2001 Uwe Clausen accepted the chair "Transport Systems and Logistics" at TU Dortmund University, which became the Institute of Transport Logistics in 2011. He is amongst others chairman of EffizienzCluster LogistikRuhr and a member of ECTRI European Conference of Transport Research Institutes and of the Scientific Advisory Board of German Logistics Association (BVL). His e-mail address is clausen@itl.tu-dortmund.de.

JAN KAFFKA was born in Münster, Germany, and attended TU Dortmund University, where he studied logistics and obtained his degree in 2008. He works at the Institute of Transport Logistics at TU Dortmund University as a scientific assistant and as a full-time $\mathrm{PhD}$ student, doing research in the fields of intermodal freight transport and simulation in traffic and transport logistics. His e-mail address is kaffka@itl.tu-dortmund.de. 